\title{
The Lived Body and Embodied Instructional Practices in Maritime Basic Safety Training
}

\author{
Martin Viktorelius ${ }^{1}$ (D) $\cdot$ Charlott Sellberg $^{2}$
}

Received: 27 April 2021 / Accepted: 25 September 2021 / Published online: 2 October 2021

(C) The Author(s) 2021

\begin{abstract}
This paper explores the role of the lived body in maritime professional training. By focusing on how instructors include students' subjective experiencing bodies as an educational resource and context for directives and demonstrations, the study aims at informing training of professionals for survival in emergency situations onboard ships. Drawing on a mobile video ethnography and on phenomenological analyses of the presence/absence of the body in experience, the study illustrates how instructors direct students' attention towards or away from their appearing corporal field depending on the stage of the training. The article documents three instructional practices incorporating students' lived embodiment during training: coping with distress by foregrounding the lived body, backgrounding the lived body for outerdirected action and imagining others'embodied experiences. The study contributes to our understanding of intercorporeal practices in instructional interaction and guidance in simulation-based vocational training.
\end{abstract}

Keywords Embodiment · Phenomenology $\cdot$ Lived body $\cdot$ Professional learning · Maritime safety training $\cdot$ Simulation

\section{Introduction}

A growing concern with embodiment, sensory expertise and bodily techniques can be seen in analyses of professional learning and instructional practices (Brône \& Ehmer, 2020). The embodied nature of learning and knowing is, however, still vastly undervalued in the literature on vocational education and training and is thus in

Martin Viktorelius

Martin.viktorelius@lnu.se

Charlott Sellberg

Charlott.sellberg@ait.gu.se

1 Faculty of Technology, Kalmar Maritime Academy, Linnaeus University, Kalmar, Sweden

2 Department of Applied IT, Division of Learning, Communication \& IT, University

of Gothenburg, Gothenburg, Sweden 
need of further investigation (Dall'Alba \& Sandberg, 2020; Hyland, 2018; Mulcahy, 2000; Somerville \& Lloyd, 2006). This has been expressed by several recent calls to focus on corporality in professional learning (Green \& Hopwood, 2015; Meyer et al., 2017), and to explore the sensorium, i.e. "the totality of the perceptual apparatus" within studies of professional work (Hockey \& Allen-Collinson, 2009). The emphasis on embodiment can also be seen in the research field known as 'body pedagogics' (Allen-Collinson et al., 2018; Andersson et al., 2013; Shilling, 2017, 2018) as well as in studies of simulator-based training and instructional interaction (Gåfvels, 2015; Lundesjö Kvart \& Melander Bowden, 2021; Sellberg \& Lundin, 2017; Weddle \& Hollan, 2010).

However, despite the demonstrated role of the body in professional learning and knowledge there has been a scant research interest in understanding how the lived body (Gallagher, 1986), and in particular how the feeling, or affective body, is thematized in vocation-educational settings. While explorations of embodiment in occupational training context have tended to focus on the body as a 'semiotic device', putting focus on the juxtaposition of verbal accounts and bodily conduct in communication (Goodwin, 2000; Lindblom, 2015; Lindwall, 2014), few have investigated how participants' experienced body is taken into account in instructional interaction and the acquisition of practical skills (Hockey, 2009; O'Loughlin, 1998). A perspective Crossley (1995) call 'carnal sociology', examining the interrelationship between social and sensory processes grounded in data from the sensuous or feeling body (Leib) rather than merely about the body as an object (Körper), is thus needed in professional education and training. Moreover, while sensory and bodily knowledge in vocational instruction has been examined to some extent, emotions are, despite their intertwinement with cognition and action, often absent from the accounts. This study examines a case of maritime basic safety training in master mariner and marine engineering programs, drawing on ethnographic fieldwork at two maritime training centers as well as video recorded interactions between students, instructors and technologies (Brown \& Lackova, 2020). By focusing the analysis on episodes where instructors address the role of feelings in different ways, the analysis aims to illustrate how the lived body is configured and topicalized by instructors in relation to the embodied conduct taking place during the training of emergency action onboard ships. We argue that this scope is essential to further our knowledge on the social and instructional practices at play in simulation-based professional training.

\section{Embodiment in Professional Instruction, Learning and Knowing}

The conceptual incoherencies associated with cartesian dualism have been debated and recognized for many years in the social and cognitive sciences (Ryle, 1949; Schön, 1984). The embodied nature of knowledge and how it is instructed has been acknowledged and explored in a number of different studies of professional education such as police training (Söderström et al., 2019), dance training (Purser, 2017), floristry education (Gåfvels, 2015), architectural education (Lymer, 2009), surgical training (Mondada, 2014; Svensson et al., 2009; Zemel \& Koschmann, 2014), dental 
education (Hindmarsh et al., 2011, 2014; Lindwall \& Lymer, 2014; Weddle \& Hollan, 2010), hairdressing education (Öhman \& Tanner, 2017) and maritime training (Sellberg, 2016; Sellberg \& Lundin, 2017). Most of this research has examined embodiment in instructional practices from an ethnomethodological/conversation analytic perspective and focused on knowing and learning as grounded in accountable situated bodily activity and practice. A prominent interest has been directed at senses or 'sensible knowledge,' that is, knowledge "perceived through the senses, judged through the senses, and produced and reproduced through the senses" (Strati, 2007, p. 62). A particular focus has been devoted to what Goodwin (1994) termed 'professional vision' and on the 'pedagogic configuration of gazes', as illustrated by Lymer (2009). Studies examining the training of professional vision have contributed to our understanding of the development of the socially and materially embedded organization of embodied skillful perception (Gåfvels, 2015; Hontvedt, 2015; Sellberg \& Lundin, 2017; Weddle \& Hollan, 2010). Drawing on a broader anthropological and phenomenological framework, some studies have focused on the socialization of other senses than the visual, such as aural knowledge and how it is traded between generations of doctors (Maslen, 2015; Rice, 2010). Emphasizing the intertwinement of senses in medical practice, Harris (2016) investigated the learning of auditory-tactile-proprioceptive skills of percussion (a type of medical examination). Arguing for an understanding of skilled senses as "an intermeshed web of perceptory apparatuses", Potter (2008) investigated kinesthesia and touch in contemporary dance training and showed how the transformation of the dancers, from students to professionals, involved a "shifted sensorium". Similarly, Hockey (2009) investigated the combination of several sensory practices (ocular, auditory, haptic and olfactory) in patrol training of infantrymen.

Acknowledging the inherent intertwinement of professional perception and action, a theme in the literature on the training and instruction of embodied knowledge addresses bodily techniques and tool use (Dall'Alba \& Sandberg, 2020; Hindmarsh et al., 2011, 2014; Lindwall \& Ekström, 2012; Lundesjö Kvart \& Melander Bowden, 2021; Marchand, 2008; O’Connor, 2007; Weddle \& Hollan, 2010). In many professions, such as surgery or craftwork, the performance of certain expert actions is often dependent on a high degree of bodily precision and skill. This competence does not just concern the use of the hands but involves the entire body and its complex dynamic couplings and interactions with a socially organized material environment (Prentice, 2007). Research addressing how bodily know-how is instructed in interaction has revealed various multimodal teaching practices used to convey the contingent and tacit nature of professional situated action and judgement. For example, Weddle and Hollan (2010, p. 128), analyzed a set of instructional practices referred to as molding and directing to "physically manipulate[s] the body of a novice into institutionally established configurations and movement patterns" used by teachers in dental hygiene. Employing a combination of speech (including metaphors, analogies and embodied conceptualizations) and gesture, the instructors were talking the students through new procedures and guided them in how to perform certain actions and use tools correctly. Similarly, Zemel and Koschmann (2014) showed how surgeons (instructors) demonstrate surgical inspection by engaging in online commentary of what they see and feel and then give directives to residents 
(students) to do the same in order for them to feel the anatomical structures referred to in the surgical reasoning of the instructor.

In addition to the treatment of the body-in-instruction as körper (objective body), seen in many of the studies above, a few studies on embodied instruction have also recognized its phenomenological, or subjective experiential, dimension (Lundesjö Kvart \& Melander Bowden, 2021; Reed, 2021). Reed (2019, p. 625) showed, for instance, how the "'felt life' of the body is topicalized and constituted by ordered practices of social interaction" during musical instruction. This was illustrated in a study of a musical masterclass and how instructors combined talk and touch to teach correct performance by sensitizing students to their own bodies and "inner experiences". Correspondingly, in Potter's (2008, p. 450) study, dance instructors used phrases such as 'melt into the floor', 'feel the weight of the head', and 'anchor the [heavy] pelvis into the ground' to make students bring their body's relationship with gravity to explicit attention. The desired effect of bodily training in these educational situations is thus to incorporate certain bodily skills, or, as described by Purser (2017, p. 323) as, "getting it into the body", conceptualized by MerleauPonty (1945/2014), as a processes of "the sedimentation of habit or bodily knowledge in the corporeal schema".

However, while the instruction of perceptual and lived bodily knowledge and techniques have been shown to play a constitutive role in the formation of students' professional competence, less has been said about its relation to emotion and affectivity during training. According to Gieser (2008), however, emotion, or the ability of being affected, plays an important role in learning a practical skill and developing know-how. Drawing on both phenomenological and neurological research, Gieser (2008) argues that emotions, which he conceive in terms of the "whole being-in-theworld of a person' and as 'context of involvements', rather than purely psychic inner states, are fundamental in learners' ways of forming associations between environmental stimuli and skilled bodily engagement. Similarly, from O'Loughlin's (1998) view, social embodiment, including individuals' bodily dispositions, orientations and attitudes, are given direction and force through emotion.

In this study we investigate how the lived, i.e., feeling or affected, body, figures in professional training and instruction. The empirical case of maritime basic safety training serves our purpose well as an example of embodied instruction because of its focus on preparing students for emotionally and physically challenging emergency situations at sea. Grounded in the analytic context of the phenomenology of the body (Gallagher \& Zahavi, 2008; Leder, 1990) and 'intercorporeality' (Meyer et al., 2017), this study aims to contribute to the literature on embodied instruction in simulation-based training and vocational learning. The next section introduces the theoretical background of the study.

\section{Phenomenology of the Body and Skill Acquisition}

The body is fundamental in human knowing, learning and communication (Meyer et al., 2017). A crucial concept for understanding the constitutive role of embodiment in interaction is the concept of the lived body. Originating in Husserl's 
(1952/1989) distinction between körper and leib, later referred to as corps vivant by Merleau-Ponty (1945/2014), the lived body can be defined as "a dynamic spatiotemporal presence anchored in the tactile-kinesthetic-affective body" (Sheets-Johnstone, 2019, p. 12). It can be contrasted with the objective or physiological body as it is known or presented through scientific methods. In other words, the lived body is associated with a certain subjective (first-person perspective) way of experiencing one's own body, including its affective states and emotions. However, rather than there being two different bodies, the objective and the lived body is one and the same, although presented in different ways to the subject and others. Being a living human body, moreover, does not imply that we always consciously experience our body in every aspect and performance (Gallagher \& Zahavi, 2008). In Drew Leder's phenomenological analysis, the living body is argued to play an ambiguous, or even paradoxical, role in our conscious experience (Leder, 1990). In the course of normal skilled coping and interaction with the world, our body tends to be absent from reflective awareness, as it "sinks into the background and does not become the object of its own experience" (Crossley, 2007, p. 82). As expressed by Leder (1990, p. 18, italics added): "one acts from the here-and-now body to spatially or temporally noncoincident objects. Furthermore, this is usually accompanied by an attentional telos outward. One's body is rendered subsidiary, not only as a physical means to an end but within the accompanying structure of attention". The 'from-to' or'figure-ground' structure, i.e., the outer-directed concern and self-effacing nature of the body, is, according to Leder (1990) essential for uninterrupted interaction and skilled functioning. According to Leder (1990), this perspective opens us up to "the stream of the world" and allows us to "reach out to others". For example, in order to strike a can with a rock from a distance one need to look at the can and not the hand throwing the rock.

Furthermore, through a process of habitualization and incorporation, tools can become "ready-to-hand" (zuhanden) (Heidegger, 1927/2010), i.e. parts or extensions of a lived yet tacit body. This means that the tool disappear in the same way as the body does in skilled coping. In an analysis of embodied knowledge in glassblowing, O'Connor (2007) argues similarly that the proficient tool-user has only subsidiary awareness of the tool in action and is guided by a practical and bodily intentionality where the tool has receded from consciousness and become an extension of the body. However, the body (including the use of a tool) does sometimes appear in certain circumstances of interactional breakdown, as when "the organism loses or changes its rapport with the environment", e.g. when fatigued or in severe pain (Gallagher, 1986, p. 148). The breakdown elicits a conscious thematization of the embodied substratum of our actions in which the body or tool, from which we were previously self-concealingly acting, now becomes that towards which we attend. Pain, anxiety, and emotional discomfort are examples of instances where the body might ' $d y s$-appear' ${ }^{1}$. In these instances we become aware of parts or aspects of our re-appearing bodies and consequently loose our initial intentional goal of our actions (Leder, 1990).

\footnotetext{
${ }^{1}$ From the Greek prefix dys signifying bad or ill.
} 
We can also become aware of our bodies when practicing a certain new skill, which often requires explicit thematization and attention to rules of performance (Leder, 1990). When learning how to play the piano, for instance, we often consciously attend our movements, making sure we are pressing the right keys, before we can concentrate on the music. According to Marchand (2008, p. 261), a heightened somatic awareness "not only endows us with a capacity for reflection on our bodily postures and actions, but it also enables us to consciously hone the accuracy and coordination of our practices". The novice's initial 'reading' of the learned practice and its tools - the abstracting, reflection and evaluation-is, as emphasized by O'Connor (2007), a necessary step in honing a skill: "the apprentice fashions her practice by making an implicit technique explicit, improving and re-aligning that technique with its intended purpose, and allowing the revised technique to again recede into unconsciousness" (O'Connor, 2007, p. 130). Hence, while we need to foreground our body when learning a new skill, we background it in mastery.

In the remainder of the paper, we illustrate a case of instructors' practices related to the absence and appearance of students' lived bodies. As will be seen in the analysis, instructors' monitoring, guidance and regulation of students' attention towards and beyond their and others' feeling bodies plays an important role in basic safety training.

\section{The Empirical Case, Method and Data}

Before entering a ship as a professional, every seafarer needs to undergo basic safety training, a five-day course promoting awareness on possible hazards on board a vessel. The course is provided early on in maritime educational programs and that seafarers revisit every 5 years as a "refresh course". Since emergency assistance from shore can be far away when sailing the seas, part of the goals of this training is to promote seafarers' ability to survive at sea in the event of ship abandonment, to be able to fight and extinguish fires onboard, as well as to take immediate action in case of medical emergencies.

Maritime policies stipulate that basic safety training should be conducted under "truly realistic training conditions (e.g., simulated shipboard conditions)". ${ }^{2}$ Consequently, practical training involves simulations that mimic emergency situations, preparing the trainees to take immediate and correct action in emergency situations. A starting point for learning how to handle emergency situations is the sensory experiences gained by participating in basic safety exercises. Such experiences include, for example, kinesthetic and thermal perception when moving in protective body suits in different elements (water or fire). Another salient feature of the exercises is to train to handle a variety of tools and technologies, for example life jackets,

\footnotetext{
2 The International Convention on Standards of Training, Certification and Watchkeeping for Seafarers (STCW), sets minimum qualification standards for masters, officers and watch personnel on board merchant ships and large yachts.
} 
Table 1 An overview of fieldwork activities

\begin{tabular}{llll}
\hline Observation & Setting & Participants & Duration \\
\hline First aid & Site 1 & 13 students, 1 instructor & $4 \mathrm{~h}$ \\
Survival techniques & Site 1 & 15 students, 2 instructors & $5 \mathrm{~h}$ \\
$\begin{array}{l}\text { Survival techniques (refresh } \\
\text { course) }\end{array}$ & Site 1 & 11 Professionals. 2 instructors & 1 day \\
Survival techniques & Site 2 & 15 students, 5 instructors & 2 days \\
Fire fighting & Site 1 & 19 students, 5 instructors & 2 days \\
Fire fighting & Site 1 & 20 students, 5 instructors & 2 days \\
Fire fighting & Site 2 & 18 students, 5 instructors & 2 days \\
\hline
\end{tabular}

evacuation chutes and slides, life rafts, fast rescue boats, firefighting equipment including breathing apparatuses as well as medical devices such as defibrillator.

\section{Method}

Methodologically, the study is designed as a mobile video ethnography (e.g., Brown \& Lackova, 2020; Spinney, 2011; Vannini, 2017). Mobile video ethnography has been described as a refined video method designed to enable researchers to accompany and follow participants on the move (Vannini, 2017). There has been an increasing use of smartphones and body-mounted cameras in recent years, in order to gain an understanding of mobile experiences (Sumartojo \& Pink, 2017). As Sumartojo and Pink (2017) emphasize, video records from such devices should be seen as video traces that follow the participants' movements in "specific environmental, sensory and affective configurations" (p. 39). Hence, mobile ethnography is a way of focusing on the sensory and embodied dimension of educational practices (Pink, 2015). During the autumn of 2020, ethnographic fieldwork was conducted at two maritime universities, observing various training activities in basic safety training courses for maritime students as well as retraining for onboard personnel, a so-called refresh course (Table 1). In order to follow the action during exercises where participants are constantly on the move, either in water or in fire and smoke, GoPro $^{\mathrm{TM}}$ cameras were mounted on participants' (students and instructors) chests or helmets. The actions were also filmed from a distance in a 'go-along' manner in order to relate different perspectives towards each other (cf. Vannini, 2017). For this purpose, smartphones were used as handheld cameras, easy to move and control as the exercises progressed.

\section{The Data Corpus and Analysis}

In all, the fieldwork covers $76 \mathrm{~h}$ of basic safety training, documented through fieldnotes, photographs and video-recorded briefings, exercises and debriefings. In addition, semi-structured interviews with seven instructors were carried out, as well as five focus group interviews with 40 students. The material was thematically scrutinized for an overall understanding of the structure and meaning of the 
training (Braun \& Clarke, 2006). This involved mapping all the different exercises included in the basic safety training course and analyzing (a) the content and purpose as described by formal documents and instructors, (b) students' and instructors' actions, interactions and talk during briefing, exercises and debriefing (as captured in fieldnotes and video-recordings) and (c) students' and instructors' reflections, opinions, feelings and evaluations related to the training (captured in the interviews and focus groups). This preliminary background analysis, generated the framing context and identified analytical hotspots (Jordan \& Henderson, 1995), which were then used for a further and more detailed analysis of the videos recorded during briefings, exercises and debriefings. In all, approximately $4 \mathrm{~h}$ of video recorded training was qualitatively analyzed by a detailed dissection of the talk and visible conduct of participants (Heath et al., 2010). In this step we started to transcribe, in verbatim, sequences of verbal utterances and bodily actions as recommended by Heath et al. (2010) to develop our preliminary observations further. The excerpts selected for inclusion in the study were chosen since they provide explicit examples of three themes found through this analytical process: foregrounding, backgrounding and imagining the lived body. In the next section, we elaborate what this means in the interactional details of basic safety training.

\section{Results}

\section{Coping with Distress by Foregrounding the Lived Body}

One of the first firefighting exercises that the students do in basic safety training is described by instructors as the 'claustrophobia-chamber'. It involves entering a completely darkened cargo container filled with 'theater' smoke (Fig. 1). The inside of the container encompasses a maze arranged in several vertical layers, or floors, running along the container side, barely fitting a human in a crawling position. When entering the container, the students are wearing protecting fire suits and a breathing apparatus including a mask connected to an air bottle on the back. An important aim of the exercise is to get students familiar with using the breathing apparatus and overcome negative emotions that might be triggered by the feeling of being trapped inside a dark and narrow compartment. In worst cases, such feelings can result in hyperventilation and, consequently, the premature depletion of the air in the tube during firefighting. Before this exercise both students and instructors were always seen to be a bit tense. Students standing in smaller groups outside the container, chatting with each other and letting out occasional nervous laughs worried about how they will react in the chamber. The instructors often gathered for a short talk before they started, informing each other about whom of the students they had identified as particularly nervous and suspected could go into panic-mode inside the chamber. During the briefing held outside the chamber instructors recapitulated and demonstrated to the students how they should mount the breathing apparatus and the technique they ought to use for breathing properly. They emphasized the importance of keeping calm and letting the instructors know if they were to feel very uncomfortable inside the chamber. One at a time, each student entered into the container, 
Fig. 1 "The claustrophobiachamber"

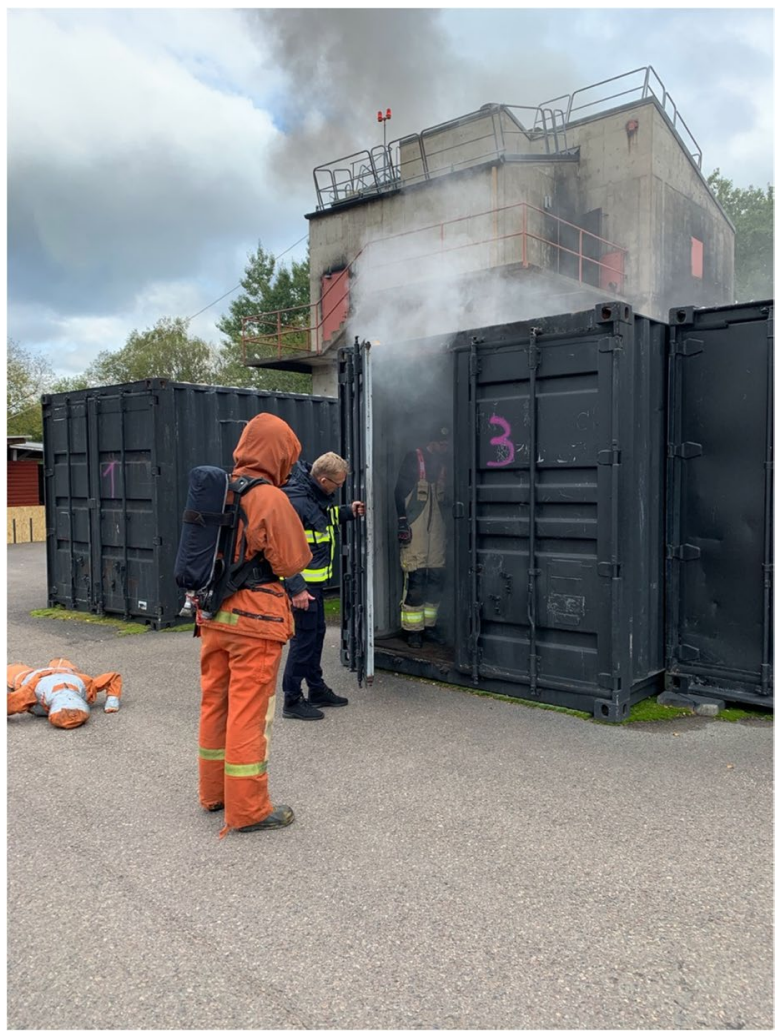

joined by an instructor who gave them continuous verbal descriptions of what the students were about to feel with their bodies (walls and turns) while crawling along the dark container. Listening to students' voice and breathing gave instructors an opportunity to evaluate their emotional state, ready to assist or stop the exercise if needed. After the exercise each student were given individual detailed feedback and an opportunity to debrief their feelings and experiences.

In the episode chosen for analysis, we join the student and instructor when standing outside the container doing a quick briefing before the exercise.

\section{Excerpt 1}

01 Ins: How are you feeling?

$02 \mathrm{Stu}: \quad(($ Shakes his head)).

03 Ins: How does it feel to have the mask on? 
04 Stu: It's a bit...it's gonna be fine... it's better... it will go fine.

05 Ins: Yes, have you tested to walk around with the mask.

Up the... just walk around a bit, how it feels?

06 Stu: ((Slight head shake, then nod)).

07 Ins: You've done that? It feels alright to have it on now?

08 Stu: ((Nodding)).

09 Ins: Yeah, mmh.

The instructor asks how the student is feeling now when he is about to enter the container with the breathing apparatus. The student makes a head movement indicating a somewhat ambivalent attitude but does not provide a verbally articulate response. The instructor reformulates the question, making it more specific this time, by asking about the feeling of wearing the mask. The student answers the question in his turn, but the utterance is made in a hesitant and ambivalent manner (Excerpt 1, line 4). The instructor continues with yet another reformulation and specification of the question about how the student feels, apparently still trying to assure himself that the student is feeling alright. The student provides an ambiguous response in his initial slight head shake immediately followed by a nod. The instructor asks for a clarification (excerpt 1, line 7) but the student only continues nodding without explicitly answering the question. The instructor provides an affirmative token indicating that he accepts the answer ("yeah, mmh") although the manner in which he provides it indicates that he is not fully convinced.

\section{Excerpt 2}

10 Ins: The breathing you have now is really good,

11 So keep calm as much as you can.

12 And take it nice and easy inside.

13 And breathe in that way.

14 If you feel that you breathe a little too fast,

15 Stop, take three deep breaths in that case. 
16 And then we'll continue after that.

Still standing outside the container but with the breathing apparatus connected to the student's mask (excerpt 2), the instructor compliments the student for breathing with the correct technique and encourages him to "keep calm". The instructor also provides the student with a coping strategy to be used if he starts breathing too fast (excerpt 2, line 14-15).

\section{Excerpt 3}

17 Ins: It never feels ok to get something over your respiratory tract but

18 Important that you tell me if you feel that it goes over a level.

19 Where you feel that this is not ok anymore.

20 Then you have to tell me directly.

21 In that case we'll call it off if that happens.

The instructor then acknowledges the normalcy of having negative emotions when getting "something over your respiratory tract" (excerpt 3, line 17) and emphasizes the importance of communicating feelings of distress or discomfort to the instructor (excerpt 3, line 18). It signals to the student that negative feelings during the exercise will not be dismissed by the instructor and that he, depending on the student's willingness to disclose his affective state, can immediately terminate the exercises if needed (excerpt 3 , line 21).

In the next excerpt, taken from the ongoing exercise, we can see that the instructor is attending to the students' movements and breathing in the maze while giving him directions (excerpt 4, line 22). The dark, smoky and narrow maze, simulating the environmental conditions during firefighting onboard a ship, requires the students to shift their everyday corporeal stance of navigating and moving around, using vision and upright walking, into a sensorimotor configuration dependent on touch and proprioception. The students are not left alone to feel their way through the maze but are guided by the instructors. A premise for this guidance is the instructors' continuous and close monitoring of the students' movements, breathing and signs of distress (cf. Sellberg \& Lundin, 2017). The instructors are not only following the students physically around in the container (there is room for the instructors to walk next to the maze inside the container), but also track the students' sensory and bodily perspective as if being inside the maze, as expressed by utterances such as "if you use the right hand and turn right then you'll surely feel a continuation towards your...”. 


\section{Excerpt 4}

22 Ins: If you use the right arm and turn right then you'll surely feel a continuation towards...

23 Stu: Right?

24 Ins: Yeah, that is left but that doesn't matter.

If you keep on turning.

Do you feel? There you feel a continuation uh?

24 Stu: Yes.

25 Ins: That's where we are going.

26 Stu: ((student is gasping and breathing heavily)).

27 Ins: Do you feel ok?

28 Stu: ((no response)).

29 Ins: Do you feel ok there, ((student name))?

$30 \mathrm{Stu}$ : Yeah.

31 Ins: Yeah, and just take your time.

Get back into the breathing in that case.

32 Stu: Its' fine so far.

33 Ins: Yeah.

34 Stu: I continue.

35 Ins: Yeah Long nice breaths, just like that yes, nice and easy, good work.

36 Stu: Yupp.

37 Ins: Wonderful, that's right.

The omitted direction word (excerpt 4 , line 22), audibly absent from the sentence, is anticipated but requested nevertheless by the student thereby indicating his desire to be further guided. While agreeing with the student's insertion, ("right?") completing his previous utterance, the instructor notices that the student has turned left rather than right. This is, as indicated by the instructor, of no relevance for the actual performance of the student (excerpt 4 , line 24), however, it constitutes a break in the alignment of perspectives, as implicitly negotiated in interaction, that both the student and the instructor have been keen to keep.

After having crawled a couple of meters into the dark and narrow tunnel the sound of the student dragging his hands and knees against the floor stops and he starts gasping for air. The instructor, who has been continually instructing the student to feel his surrounding and find the way with his hands, notices that the student has troubles breathing normally. The gasping for air is directly and immediately perceived by the instructor as an instance of student-in-distress (excerpt 4, line 26-27). This can be understood as an act of empathy defined as a "form of intentionality in which one [in this case the instructor] is directed towards the other's [the student's] lived experiences" (Gallagher \& Zahavi, 2008, p. 183). From a phenomenological perspective, the student's affective and emotional states of distress and discomfort are not simply qualities of his subjective experience, hidden from the instructor's view, but are rather, "given in expressive phenomena, i.e. they are expressed in bodily gestures and action [the gasping]" (Gallagher \& Zahavi, 2008, p. 182). It is based on this expressive behavior of the student's affective state that the instructor then poses his question "Do you feel ok?". The question, however, is not responded to by 
the student and the instructor therefore restates his question "Do you feel ok there, [student name]?"), in order to make sure that the student is not experiencing too much discomfort to proceed with the exercise. The subsequent response from the student indicating that he is fine and does not want to terminate the exercise (excerpt 4 , line 32,34 ) prompts the instructor to repeat the advice he gave the student before they entered into the maze: "take your time... get back into your breathing again in that case". The directive is an encouragement to shift attention from an external, or distal, sensory perspective directed at sensing the walls and spatial positioning with the hands, to an internal, or proximal, perspective focusing on the body doing the sensing and crawling, and in particular to make the student attend his own breathing in order to cope with his distress. Hence, while the instructions before the student's emotional expression of distress were focused on acting and perceiving, from the body to the environment, the new instructions thematized the subsidiary, or tacit, bodily ground of his actions (cf. Leder, 1990; Polanyi, 1962).

\section{Backgrounding the Lived Body for Outer-Directed Action}

The next episode can be seen to contrast with the previous in how the instructor treats the students' affectivity in relation to a particular exercise. While the first exercise, described above, isolated and focused on a subcomponent of firefighting (breathing with a mask and navigating in darkness) the next episode comes from the final exercise where the students had to perform all the tasks involved in real firefighting (hose handling, search and rescue, and fire extinguishing). We join the exercise at the very last minutes when two students are struggling with the rescue of an unconscious person (life sized mannequin). They have dragged the helpless person from where they found him/her inside the burning ship (made out of several connected containers at the training center) and although they are approaching the escape egress they are running out of energy to carry the person any further.

The instructor notices that the students' tempo has decreased and that they have troubles carrying the mannequin the remaining few meters to which he responds by yelling "come on, come on, all the way". One of the students drops the mannequin and falters to the side where he falls to the ground totally exhausted. The instructor sees this but continues to shout to the remaining student to "take it out". The student reaches down for the mannequin and utters that she "cannot bear it anymore". Ignoring this the instructor yells to her to "come on", "bend down" and "pull". The student makes a new attempt to lift the mannequin and this time she manages to pull it a bit further out from the container to the satisfaction of the instructor who affirms the action and evaluates it as sufficient by uttering "good". He then walks up to the other exhausted student sitting on the ground with his head down breathing heavily, gives him a clap on the shoulder and says: "good work, we are going up the staircase now, I'll follow you" (Fig. 2). The student's bodily conduct (stumbling away from the ongoing rescue operation despite the instructor's directive to keep on) and posture (collapsed with inclined head, supporting his upper body with one arm against the ground) can be seen as an intersubjectively accessible expression of his affective state (Gallagher \& Zahavi, 2008). Although the student's visible fatigue and 
Fig. 2 Instructor and collapsed student

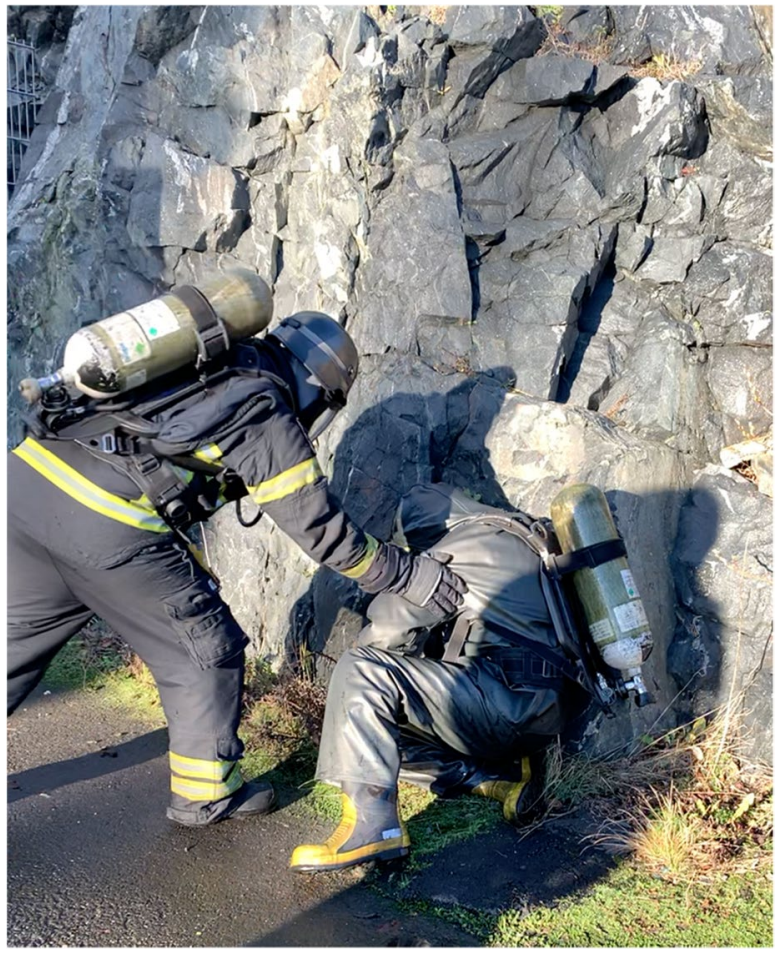

discomfort is noticed by the instructor, as indicated by his approach to the student coupled with a verbally approving appraisal ("good work") and encouraging gesture (clap on shoulder), it is not explicitly addressed. His imperative formulation "we are going up", does not invite the student to express himself or choose to stay in the resting position. The student stands up and all three of them re-enter the burning ship simultaneously as the instructor affirms both students for doing a "good work".

\section{Excerpt 5}

01 Ins Last bit

02 Good, that way, come on.

03 Come on, come on, all the way.

04 Take it out, take it out.

$05 \mathrm{Stu}$ I can't bear it anymore. 
06 Ins Come on, come on, bend down.

07 And pull and pull, good.

08 Good work, we're going up the stairs now, I'll follow you, come.

09 Keep together, we're going in.

10 Good work, good you made it.

It is noteworthy that the instructor does not encourage, or allow, the students to attend to their bodily experiences in this situation, as opposed to the interaction seen in the first episode (excerpt 1-4) but is directing them to keep on going despite their hearable and visible fatigue. The instructor waits until after the exercise (a few moments past the excerpt) with asking the student that collapsed how he experienced the last minutes of the exercise ("Was it heavy?") coupled, once again, with a hand on his shoulder. This can be contrasted to the first episode where the instructor was asking about the student's feeling during the exercise. The excerpt suggests that the instructor does not simply fail to perceive the students as being exhausted but is intentionally pushing them. The instructor is, as in the first episode, monitoring and responding to the students' affective display although he does not acknowledge the time and place as appropriate for rest or bodily self-reflection. The body must not appear at this critical moment of the operation and an outer-directed focus on the actions intentional goal ought to be maintained. The episode illustrates how the instructor uses the students' affective state and bodily experiences as a means to enact important lessons of the exercise, in this case to keep the tempo and bring all injured persons to the safe zone outside the burning ship, even if that means pushing their own bodies. Moreover, the exercise illustrated in first episode (excerpt 1-4) was enacted as less authentic in that the instructor encouraged the student to stop whenever he felt distress and directed the student to focus, intra-subjectively, on his bodily state. In excerpt 5 , in contrast, the instructor is enacting a different situation; one that should reflect a real fire in which the student has no time to focus on his feelings but has to suppress his distress for the moment and carry out the task.

\section{Imagining Others' Embodied Experiences}

Although the exercises are conducted in daylight and nice weather condition, they are meant to prepare students for situations which might involve darkness, coldness and stormy weather. The exercises were therefore lacking in realism and authenticity in relevant regards (Rystedt \& Sjöblom, 2012). The discrepancy between reality and training was, however, not only of a physical kind, but, more importantly, of a psychological and emotional nature (Hontvedt \& Øvergård, 2019). The final episode analyzed in the paper illustrates yet another way in which instructors configured the affective body into the basic safety training of the students. 


\section{Excerpt 6}

01 Ins Some of you jumped yesterday from the... with the survival suit?

02 Was it unpleasant?

03 Not at all? A bit?

04 When you get up there four five meters then it is...

05 You start wondering a bit.

06 I think so at least.

07 Reflect standing here instead.

08 There you see that little raft.

09 And here you have a crew member that...

10 It's pitch-black.

11 Fully crammed with timber around.

12 And you know that if I jump, if I miss the raft then I'll die.

13 That's actually the situation they are in, right.

Excerpt 6 illustrates an instance, during the debriefing on the second day of training, of an instructor trying to contextualize the embodied conduct of the students and add a layer of meaning to the simulations. The instructor, who is an experienced surface rescuer, has been showing movie clips he has found on YouTube on actual maritime accidents and emergency operations (Fig. 3). He starts by confessing that even an experienced professional like him can find it unpleasant to jump from a ship, thereby recognizing the students' emotions (excerpt 6, line 6). But then he contrasts that feeling with the feeling of standing "here instead". The indexical "here" refers to the deck of a real sinking ship in the middle of a stormy ocean as captured in the movie clip filmed from a rescue helicopter. The instructor has stopped the clip and is pointing, interchangeably, to the crew member standing on that deck and the raft he is about to jump into. The utterance "reflect standing here" is, moreover, an encouragement to the students to imagine that position from a first-person perspective, as if being the crew member on the ship. The instructor's narrational contextualization continues by an explication of the conditions and stakes characterizing the situation as seemingly hopeless in that moment. The use of the present tense ("it is pitch 


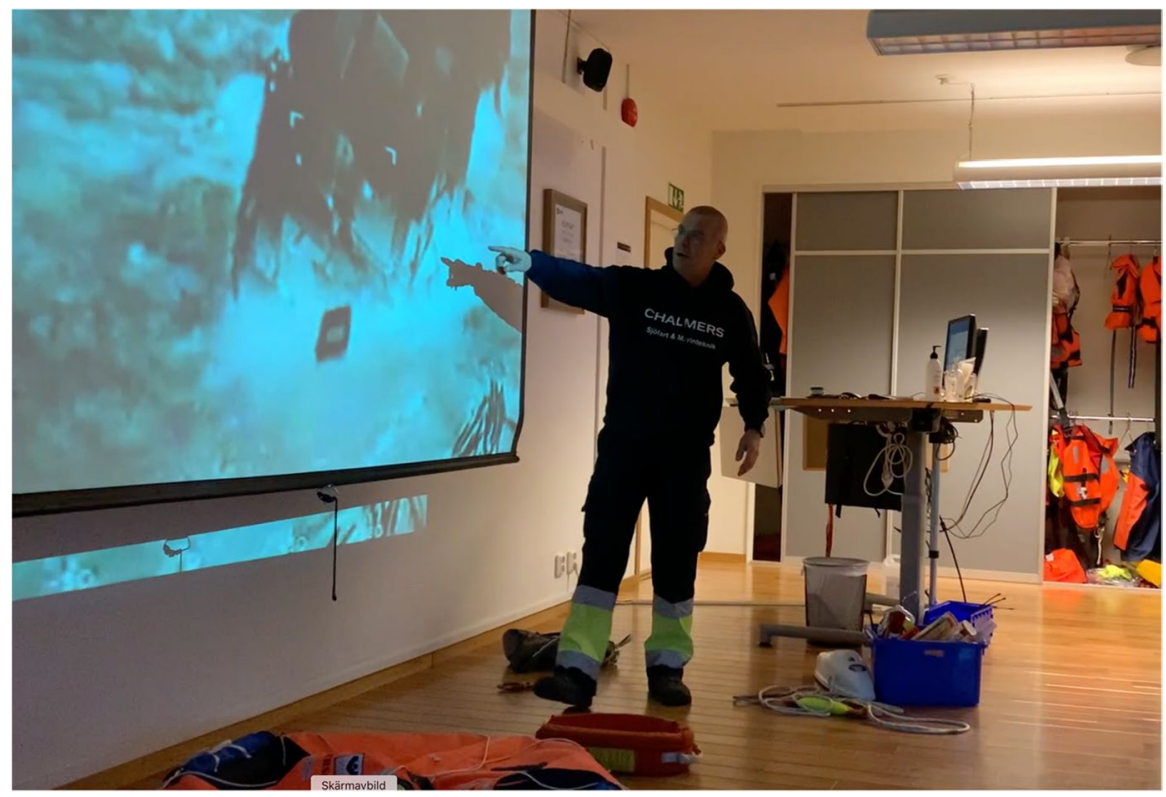

Fig. 3 Instructor showing YouTube clip from accident

black") and first personal pronoun ("if I jump, if I miss the raft, then I'll die"), can be seen as an attempt to bring the story to life in front of the students.

Following this the instructor shows a sequence when the crew member jumps but misses the raft. The situation, as represented in the filmed event, is then used by the instructor to contrast the students' personal embodied experience of climbing into a raft (as part of one of their exercises) with the challenge of getting inside a raft in full storm and after "three four hours" in the water.

\section{Excerpt 7}

14 Ins And what happens? Misses the raft, or rather, grabs it from the outside.

15 What is this person's task now?

The only thing he or she has to do?

$16 \mathrm{Stu}$ Get into the raft

17 Ins Get into the raft, yes 
18 Some of you did it yesterday, some will do it today

19 It is a challenge to get into a raft

20 Even when you're alert and fresh and have had a coffee

21 We don't know how tired they are, after three four hours here

The narrative does not, however, end with how slim the chances of survival are for the crew on this ship. In fact, the 30 min movie clip ends with the whole crew being rescued by another ship after $10 \mathrm{~h}$ in the water. The intended lesson of the narrative is repeated by the instructor several times during the viewing and is illustrated in excerpt 8 . The instructor stops the clip again, walks closer to the projection screen in front of the classroom, points toward the crew member in the water and directs the students to "look at this person". The pausing of the clip, the gestural highlighting and the verbal emphasis signals the importance of what is to be said. In the next three lines the instructor summarizes the take home message of the lecture: never give up, work hard and you will be able to survive.

\section{Excerpt 8}

22 Ins: Look at this person

He has no idea whatsoever that we film him

But look how he is working here

This person hasn't given up

Working, working, all the time, maybe he has been working for half an hour, we don't know when they film

But 22.44 continues to work, gets out from the timber and is taken up

So the helicopter can come and take up this person at last

He does not give up, he does not stop work, or she, and is saved

Hence, the instructor attempts, with the use of visualization, gesture and narration, to make students relate the simulated scenarios the day before with the enacted events taking place on that disastrous night, including the crew members' extensive struggle to survive. This requires the students to not only understand the objective risks of the situation but also imagine the crew members' subjective perspective, 
thoughts and feelings of being onboard the sinking ship. It is, more specifically, the narrative of the crew members' embodied affectivity, and its imagined phases of initial hopelessness, subsequent fight and motivation and final rescue and relief, as enacted by the instructor using the movie clip and comments, that is topicalized. This appeal to students' emphatic and intersubjective understanding of the crew members embodied situation, and the instructional work facilitating such an identification, can be seen as an attempt to retrospectively increase the emotional fidelity of the exercise.

\section{Discussion and Conclusions}

Following the 'embodied turn' in educational research (Brône \& Ehmer, 2020; Dall'Alba \& Sandberg, 2020; Green \& Hopwood, 2015), this study aimed to explore the institutionalized means used by instructors in molding students' affective embodied experiences in basic safety training. The motivation for the study was derived from the lack of studies investigating the lived body (Gallagher, 1986; Gallagher \& Zahavi, 2008) in research on simulation-based professional education and training and instructional interaction concerned with embodiment.

The study illustrates how maritime students are socialized into professional ways of acting in emergency situations and how students' lived experience of their own bodies and emotions are rendered into an instructional resource for teachers in basic safety training. The training involved instilling in students an embodied sense and understanding of what it means to be in an emergency situation and, more importantly, what aspects of their corporal experiential field to attend and what to suppress in order to stay alive and help saving others (e.g., proper breathing is crucial but fatigue must be ignored).

Three instructional practices, in which instructors oriented towards students' bodily states, were identified. In the first type of instructional practice (4.1 foregrounding the lived body) affective states were acknowledged by instructors who also encouraged students to attend to their bodies in order for students to take control of their feelings by applying one or another coping technique. In the second type of instructional practice ( 4.2 backgrounding the lived body), however, students were encouraged to focus from the felt body on the task at hand despite strong discomfort. The third instructional practice (4.3 Imagining others' embodied experiences) was motivated by the discrepancy, regarding emotional and experiential fidelity of the exercises, between the possibilities of creating simulated emergency scenarios in training and actual instances of firefighting and ship abandonment (Hontvedt, 2015; Rystedt \& Sjöblom, 2012; Sellberg, 2017). Here, the use of narration and visualization was used as a tool by the instructor during debriefing to create an opportunity for the students to reflect on their embodied experiences from the previous exercises.

The three practices form a continuation or trajectory corresponding to the phenomenology of skill development (Dreyfus \& Dreyfus, 2005; Leder, 1990). The first practice of directing students' conscious awareness towards their own body and tool use, rather than the goal of the action, resonates with the initial stages of learning where the novice is thematizing rules and procedures. The second practice focuses 
on the goal of the task (e.g. extinguish fire and rescue person), and requires conscious bodily experiences and rules to recede in awareness. The last practice represents the most mature in which the student is encouraged to reflect on experience and expand its meaning to situations not possible to simulate in an educational setting.

The study demonstrates the social and interactional significance of the lived body in professional training and contributes to our understanding of the cultural transmission of embodied practices, skills and affective attitudes (Shilling, 2017). The analysis illustrated the interplay between students' lived bodies during exercises and instructors' practices of guiding students through their experiences. The instructions analyzed aimed to steer the students' attention towards or away from their bodily awareness and make them reflect on certain experiences when appropriate. It shows how instructors exhibited a sensitivity not only to students' objective actions (körper) but also to their lived bodies and affective states during training. The exercises were accomplished in and through the interactions between, on the one hand, students embodied conduct and reactions during exercises and, on the other, instructors' ability to apprehend students' emotional and bodily states to give appropriate support. The instructors' close monitoring of students' behavioral expressions of their affective states allowed them to fashion directives with regard to the students emotional and physical experience, while taking into account the purpose of particular exercises. Instructors thus included students' emotional bodily states as the context against which directives were given and thus helped the students navigate their inner subjective world during the exercises. Finally, further research on intersubjectivity, corporeality and embodied professional learning is needed and we hope to have inspired other researchers to engage in this area of study.

Funding Open access funding provided by Linnaeus University.

Open Access This article is licensed under a Creative Commons Attribution 4.0 International License, which permits use, sharing, adaptation, distribution and reproduction in any medium or format, as long as you give appropriate credit to the original author(s) and the source, provide a link to the Creative Commons licence, and indicate if changes were made. The images or other third party material in this article are included in the article's Creative Commons licence, unless indicated otherwise in a credit line to the material. If material is not included in the article's Creative Commons licence and your intended use is not permitted by statutory regulation or exceeds the permitted use, you will need to obtain permission directly from the copyright holder. To view a copy of this licence, visit http://creativecommons.org/licen ses/by/4.0/.

\section{References}

Allen-Collinson, J., Crust, L., \& Swann, C. (2018). Embodiment in high-altitude mountaineering: Sensing and working with the weather. Body \& Society, 25(1), 90-115. https://doi.org/10.1177/13570 $34 \times 18812947$

Andersson, J., Östman, L., \& Öhman, M. (2013). I am sailing-Towards a transactional analysis of 'body techniques.' Sport, Education and Society, 20(6), 722-740. https://doi.org/10.1080/13573322.2013.802684

Braun, V., \& Clarke, V. (2006). Using thematic analysis in psychology. Qualitative Research in Psychology, 3(2), 77-101. https://doi.org/10.1191/1478088706qp063oa 
Brown, K. M., \& Lackova, P. (2020). Mobile video methods and wearable cameras. In P. Vannini (Ed.), The Routledge International Handbook of Ethnographic Film and Video. Routledge.

Brône, G., \& Ehmer, O. (2020). Instructing embodied knowledge. Multimodal approaches to interactive practices for knowledge constitution. Linguistics Vanguard. https://doi.org/10.1515/lingv an-2021-0012

Crossley, N. (1995). Merleau-Ponty, the elusive body and carnal sociology. Body \& Society, 1(1), 43-63.

Crossley, N. (2007). Researching embodiment by way of 'body techniques.' The Sociological Review, 55(1_suppl), 80-94. https://doi.org/10.1111/j.1467-954X.2007.00694.x

Dall'Alba, G., \& Sandberg, J. (2020). Bodily grounds of learning: Embodying professional practice in biotechnology. Studies in Higher Education. https://doi.org/10.1080/03075079.2019.1711047

Dreyfus, H. L., \& Dreyfus, S. E. (2005). Peripheral vision: Expertise in real world contexts. Organization Studies, 26(5), 779-792. https://doi.org/10.1177/0170840605053102

Gallagher, S. (1986). Lived body and environment. Research in Phenomenology, 16, 139-170.

Gallagher, S., \& Zahavi, D. (2008). The phenomenological mind. Routledge.

Gieser, T. (2008). Embodiment, emotion and empathy: A phenomenological approach to apprenticeship learning. Anthropological Theory, 8(3), 299-318. https://doi.org/10.1177/1463499608093816

Goodwin, C. (1994). Professional vision. American Anthropologist, 96(3), 606-633.

Goodwin, C. (2000). Action and embodiment within situated human interaction. Journal of Pragmatics, 32(10), 1489-1522.

Green, B., \& Hopwood, N. E. (2015). The body in professional practice, learning and education: Body/ practice. Springer.

Gåfvels, C. (2015). Vision and embodied knowing: The making of floral design. Vocations and Learning, 9(2), 133-149. https://doi.org/10.1007/s12186-015-9143-2

Harris, A. (2016). Listening-touch, affect and the crafting of medical bodies through percussion. Body \& Society, 22(1), 31-61. https://doi.org/10.1177/1357034X15604031

Heath, C., Hindmarsh, J., \& Luff, P. (2010). Video in qualitative research. Sage Publications.

Heidegger, M. (1927/2010). Being and Time (J. Stambaugh, Trans.). Suny Press.

Hindmarsh, J., Hyland, L., \& Banerjee, A. (2014). Work to make simulation work: 'Realism', instructional correction and the body in training. Discourse Studies, 16(2), 247-269. https://doi.org/10. $1177 / 1461445613514670$

Hindmarsh, J., Reynolds, P., \& Dunne, S. (2011). Exhibiting understanding: The body in apprenticeship. Journal of Pragmatics, 43(2), 489-503. https://doi.org/10.1016/j.pragma.2009.09.008

Hockey, J. (2009). 'Switch on': Sensory work in the infantry. Work, Employment and Society, 23(3), 477493. https://doi.org/10.1177/0950017009337065

Hockey, J., \& Allen-Collinson, J. (2009). The sensorium at work: The sensory phenomenology of the working body. The Sociological Review, 57(2), 217-239. https://doi.org/10.1111/j.1467-954X.2009. 01827.x

Hontvedt, M. (2015). Professional vision in simulated environments-Examining professional maritime pilots' performance of work tasks in a full-mission ship simulator. Learning, Culture and Social Interaction, 7, 71-84. https://doi.org/10.1016/j.lcsi.2015.07.003

Hontvedt, M., \& Øvergård, K. I. (2019). Simulations at Work-A framework for configuring simulation fidelity with training objectives. Computer Supported Cooperative Work (CSCW), 29(1-2), 85-113. https://doi.org/10.1007/s10606-019-09367-8

Husserl, E. (1952/1989). Ideas pertaining to a pure phenomenology and to a phenomenological philosophy: Second book studies in the phenomenology of constitution (R. Rojcewicz \& A. Schuwer, Trans.). Kluwer.

Hyland, T. (2018). Embodied learning in vocational education and training. Journal of Vocational Education \& Training, 71(3), 449-463. https://doi.org/10.1080/13636820.2018.1517129

Jordan, B., \& Henderson, A. (1995). Interaction analysis: Foundations and practice. The Journal of the Learning Sciences, 4(1), 39-103.

Leder, D. (1990). The absent body. University of Chicago Press.

Lindblom, J. (2015). Embodied social cognition (Vol. 26). Berlin: Springer.

Lindwall, O. (2014). The body in medical work and medical training: An introduction. Discourse Studies, 16(2), 125-129. https://doi.org/10.1177/1461445613514671

Lindwall, O., \& Ekström, A. (2012). Instruction-in-interaction: The teaching and learning of a manual skill. Human Studies, 35(1), 27-49. https://doi.org/10.1007/s10746-012-9213-5 
Lindwall, O., \& Lymer, G. (2014). Inquiries of the body: Novice questions and the instructable observability of endodontic scenes. Discourse Studies, 16(2), 271-294. https://doi.org/10.1177/1461445613 514672

Lundesjö Kvart, S., \& Melander Bowden, H. (2021). Instructing equestrian feel: On the art of teaching embodied knowledge. Scandinavian Journal of Educational Research. https://doi.org/10.1080/ 00313831.2020 .1869076

Lymer, G. (2009). Demonstrating professional vision: The work of critique in architectural education. Mind, Culture, and Activity, 16(2), 145-171. https://doi.org/10.1080/10749030802590580

Marchand, T. H. J. (2008). Muscles, morals and mind: Craft apprenticeship and the formation of person. British Journal of Educational Studies, 56(3), 245-271. https://doi.org/10.1111/j.1467-8527.2008. 00407.x

Maslen, S. (2015). Researching the senses as knowledge. The Senses and Society, 10(1), 52-70. https:// doi.org/10.2752/174589315x14161614601565

Merleau-Ponty, M. (1945/2014). Phenomenology of perception (A. Landes, Donald, Trans.). Routledge.

Meyer, C., Streeck, J., \& Jordan, J. S. (2017). Intercorporeality: Emerging socialities in interaction. Oxford University Press.

Mondada, L. (2014). Instructions in the operating room: How the surgeon directs their assistant's hands. Discourse Studies, 16(2), 131-161. https://doi.org/10.1177/1461445613515325

Mulcahy, D. (2000). Body matters in vocational education: The case of the competently trained. International Journal of Lifelong Education, 19(6), 506-524. https://doi.org/10.1080/02601370050209041

O'Connor, E. (2007). Embodied knowledge in glassblowing: The experience of meaning and the struggle towards proficiency. The Sociological Review, 55(1_suppl), 126-141. https://doi.org/10.1111/j. 1467-954X.2007.00697.x

Öhman, A., \& Tanner, M. (2017). Creating space for students' concerns: Embodied feedback practices in hairdressing education. Learning, Culture and Social Interaction, 14, 79-93. https://doi.org/10. 1016/j.lcsi.2017.04.005

O'Loughlin, M. (1998). Paying attention to bodies in education: Theoretical resources and practical suggestions. Educational Philosophy and Theory, 30(3), 275-297. https://doi.org/10.1111/j.1469-5812. 1998.tb00328.x

Pink, S. (2015). Doing sensory ethnography. Sage.

Polanyi, M. (1962). Personal knowledge: Towards a post-critical philosophy. University of Chicago Press.

Potter, C. (2008). Sense of motion, senses of self: Becoming a dancer. Ethnos, 73(4), 444-465. https:// doi.org/10.1080/00141840802563915

Prentice, R. (2007). Drilling surgeons: The social lessons of embodied surgical learning. Science, Technology, \& Human Values, 32(5), 534-553. https://doi.org/10.1177/0895904805303201

Purser, A. (2017). 'Getting it into the body': Understanding skill acquisition through Merleau-Ponty and the embodied practice of dance. Qualitative Research in Sport, Exercise and Health, 10(3), 318332. https://doi.org/10.1080/2159676x.2017.1377756

Reed, D. J. (2019). Touch and talk: Detailing embodied experience in the music masterclass. Social Semiotics, 30(5), 625-645. https://doi.org/10.1080/10350330.2019.1631431

Reed, D. J. (2021). Situating embodied instruction-Proxemics and body knowledge. Linguistics Vanguard. https://doi.org/10.1515/lingvan-2020-0131

Rice, T. (2010). Learning to listen: Auscultation and the transmission of auditory knowledge. Journal of the Royal Anthropological Institute, 16(s1), S41-S61. https://doi.org/10.1111/j.1467-9655.2010. 01609.x

Ryle, G. (1949). The concept of mind. Pinguin.

Rystedt, H., \& Sjöblom, B. (2012). Realism, authenticity, and learning in healthcare simulations: Rules of relevance and irrelevance as interactive achievements. Instructional Science, 40(5), 785-798. https://doi.org/10.1007/s11251-012-9213-x

Schön, D. A. (1984). The reflective practitioner: How professionals think in action (Vol. 5126). Basic books.

Sellberg, C. (2016). Representing and enacting movement: The body as an instructional resource in a simulator-based environment. Education and Information Technologies, 22(5), 2311-2332. https:// doi.org/10.1007/s10639-016-9546-1

Sellberg, C. (2017). From briefing, through scenario, to debriefing: The maritime instructor's work during simulator-based training. Cognition, Technology \& Work, 20(1), 49-62. https://doi.org/10.1007/ s10111-017-0446-y 
Sellberg, C., \& Lundin, M. (2017). Demonstrating professional intersubjectivity: The instructor's work in simulator-based learning environments. Learning, Culture and Social Interaction, 13, 60-74. https://doi.org/10.1016/j.lcsi.2017.02.003

Sheets-Johnstone, M. (2019). The lived body. The Humanistic Psychologist, 48(1), 28.

Shilling, C. (2017). Body pedagogics: Embodiment, cognition and cultural transmission. Sociology, 51(6), 1205-1221. https://doi.org/10.1177/0038038516641868

Shilling, C. (2018). Embodying culture: Body pedagogics, situated encounters and empirical research. The Sociological Review, 66(1), 75-90. https://doi.org/10.1177/0038026117716630

Somerville, M., \& Lloyd, A. (2006). Codified knowledge and embodied learning: The problem of safety training. Studies in Continuing Education, 28(3), 279-289. https://doi.org/10.1080/0158037060 0947538

Spinney, J. (2011) A Chance to Catch a Breath: Using Mobile Video Ethnography in Cycling Research. Mobilities 6(2) 161-182 https://doi.org/10.1080/17450101.2011.552771

Strati, A. (2007). Sensible knowledge and practice-based learning. Management Learning, 38(1), 61-77. https://doi.org/10.1177/1350507607073023

Sumartojo, S., \& Pink, S. (2017). Empathetic visuality: GoPros and the video trace. In E. Gómez-Cruz, S. Sumartojo, \& S. Pink (Eds.), refiguring techniques in digital visual research (pp. 39-50). Springer.

Svensson, M. S., Luff, P., \& Heath, C. (2009). Embedding instruction in practice: Contingency and collaboration during surgical training. Sociology of Health \& Illness, 31(6), 889-906. https://doi.org/ 10.1111/j.1467-9566.2009.01195.x

Söderström, T., Lindgren, C., \& Neely, G. (2019). On the relationship between computer simulation training and the development of practical knowing in police education. The International Journal of Information and Learning Technology, 36(3), 231-242. https://doi.org/10.1108/ijilt-11-2018-0130

Vannini, P. (2017) Low and Slow: notes on the production and distribution of a mobile video ethnography. Mobilities 12(1) 155-166 https://doi.org/10.1080/17450101.2017.1278969

Weddle, A. B., \& Hollan, J. D. (2010). Professional perception and expert action: Scaffolding embodied practices in professional education. Mind, Culture, and Activity, 17(2), 119-148. https://doi.org/10. 1080/10749030902721754

Zemel, A., \& Koschmann, T. (2014). 'Put your fingers right in here': Learnability and instructed experience. Discourse Studies, 16(2), 163-183. https://doi.org/10.1177/1461445613515359

Publisher's Note Springer Nature remains neutral with regard to jurisdictional claims in published maps and institutional affiliations.

Martin Viktorelius research interests include the relation between technology, work practice, professional knowledge and learning. His main interests are oriented towards the education and training of embodied skills as well as the implementation, adoption and use of digital and automated technologies in complex socio-technical work environments.

Charlott Sellberg has a multidisciplinary background in Cognitive Science, Human-Computer Interaction and Education. Her main interests are oriented towards topics related to the use of digital technologies in education, interaction between humans and the tools they use, as well as towards theories of learning and qualitative research methods 